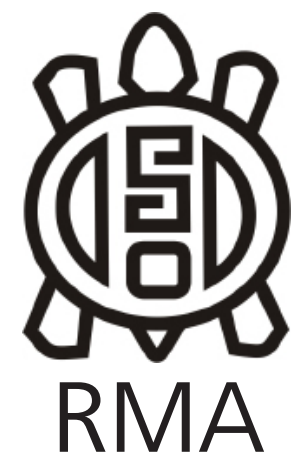

Museología

\title{
A biografia do objeto: Aporte para o estudo de cultura material no contexto museal
}

\author{
Object biography: Support for the study of material culture in the \\ museal context
}

Priscila Maria de Jesus*

*Departamento de Museologia, Universidade Federal de Sergipe, Brasil.

E-mail: priscilamdj@gmail.com

\begin{abstract}
Resumo
Parte para uma discussão sobre cultura material africana e a biografia dos objetos museais, tendo por eixo norteador um par de pesos para medir ouro em pó, peças em exposição e que fazem parte do acervo do Museu Afro-Brasileiro (CEAO/UFBA/Brasil), compreende-se o universo simbólico das produções imagéticas nigerianas, sobretudo, no que se refere às representações do ato sexual. Tendo por metodologia a pesquisa documental, por meio do levantamento de literatura que versava sobre o tema, bem como a documentação museológica dos objetos, a pesquisa analisa o universo simbólico de uma das sociedades africanas no antigo Benin, onde é hoje a Nigéria, inter-relacionando aos ritos de fertilidade da mulher, fecundidade da terra e a concepção de origem da vida nessas sociedades.
\end{abstract}

Palavras-chave: Cultura Material; Artes Africanas; Biografia do objeto; Museu.

\begin{abstract}
Part of a discussion about African material culture and the biography of museal objects, having as its guiding axis a pair of weights to measure gold dust, exhibited pieces that are part of the collection of the Afro-Brazilian Museum (CEAO/UFBA/Brazil), we understand the symbolic universe of Nigerian imagery productions, especially with regard to the representations of the sexual act. Having as methodology the documentary research, through the literature survey on the subject, as well as the museological documentation of the objects, the research analyzes the symbolic universe of one of the African societies in the old Benin, where today is Nigeria, relating to the fertility rites of women, fertility of the earth and the conception of origin of life in these societies.
\end{abstract}

Keywords: Material Culture; African Arts; Object Biography; Museum.

\section{Introdução}

O estudo de acervo museológico permite ao pesquisador e ao funcionário de museu uma miríade de possibilidades desde a compreensão do objeto à forma como ele será exposto, na qual se investiga e mostra os rastros deixados por determinado objeto ao longo da história, seja por meio daqueles que o utilizaram, como o utilizaram, como chegaram ao museu e sua trajetória dentro do museu. Desta forma, se utilizará o termo biografia do objeto, uma vez que se busca traçar a história de vida do objeto dentro e fora da instituição museológica, bem como alcançar seus significados e interpretações possíveis, destacando o seu contexto original e, posteriormente, como traduzir isso em informação para o público. Esse estudo é como um livro sem fim, no qual deve-se estar constantemente debruçado e buscando encontrar novas informações, complementar ou rescrever as que se tem com o intuído de trazer o maior grau de informação ao conteúdo disposto na documentação do objeto e no circuito expositivo.
Nesse entremeio da informação, o objeto é o ponto de partida e de chegada para as reflexões que serão lançadas, seja pelo pesquisador para sua posterior comprovação por meio dos estudos de cultura material, seja pelo visitante, que o analisará, inicialmente, tendo por base sua bagagem socioeconômica e cultural, o que torna impossível mensurar os impactos e reflexões que tal objeto suscitará em um primeiro contato. Segundo Ulpiano Bezerra de Meneses o objeto "não mente. A integridade física do artefato corresponde sua verdade objetiva. Os discursos sobre o artefato é que podem ser falsos." (1998, p. 91-92). Nota-se aqui discursos sobre a forma como esse objeto museal pode ser apresentado e visto na documentação, pelo pesquisador ou até mesmo pelo visitante. Para uma melhor compreensão desse processo e sua análise, foi concebido o fluxograma presente na Figura 1, que busca destacar os principais pontos da trajetória do objeto de museu.

Conhecer o objeto de museu e sua materialidade permite 
conhecer aqueles que a produziram e como viveram, traz um olhar diferenciado e estético sobre a história de uma sociedade, como ressalta Miller ao destacar a oposição entre pessoa e coisa, produtor e produto, autor e obra "possa demonstrar como e por quê uma apreciação mais profunda das coisas nos levará a uma apreciação mais profunda das pessoas" (Miller, 2013, p. 12). Desta forma infere-se que o estudo da cultura material, embora não seja completamente clara sua definição, pode-se dizer que em um primeiro momento seria conhecer não só o objeto, mas também a-(s) pessoa-(s) que o produziram ou utilizaram.

Destaca-se o papel da documentação museológica para acompanhar e recuperar o fluxo dessas informações. Esses processos buscam normatizar, dar uma ordem de sucessão dos fatos e como eles ocorrem dentro do museu, bem como determinar como esses conteúdos ou objetos são representados dentro dos museus. Para Lara:

Ao classificar (e indexar) segmentamos o conteúdo a partir de referências que já possuímos, formando agrupamentos em função de suas propriedades comuns, ou mais exatamente, das características que julgamos pertinentes para os nossos propósitos, já que nunca esgotamos as propriedades das coisas e fenômenos. (2001, p. 02).

Desta forma tentamos agrupar tudo aquilo que achamos semelhante, com características distintas em uma mesma classificação, permitindo uma possível unificação de linguagem e compreensão.

Segundo Ferreira, "Todo o debate sobre as categorias e modelos classificatórios adequados ou não para se lidar com os objetos etnográficos tem em comum o fato da valorização não se dar pelo objeto em si, mas pela possibilidade de incorporá-lo em modelos explicativos." (2011, p. 89). Ao se por em discussão os processos de análise e tratamento dos objetos etnográficos, não enquanto produções artísticas, que apresentam uma estética própria e capaz de suscitar sensações e interpretações por parte de seu público, mas enquanto marcadores identitários de uma determinada sociedade.

Benchimol e Pinheiro (2009) ressaltam o cuidado que se deve ter ao estudar um objeto que venha de coletas de grupos étnicos, como os pesos para medir ouro, para que não se foque mais nos aspectos de quem coletou o objeto e não de quem o produziu, dificultando, assim, o processo de compor a biografia do objeto. Ressaltam ainda, o papel do museu, enquanto espaço legitimador das produções artísticas de outras sociedades e seu difusor.

Essa valorização da história, do pensamento e da voz das sociedades produtoras dos objetos etnográficos é uma discussão recorrente entre alguns antropólogos e indica possibilidades diferentes na forma de documentar e de montar exposições em museus que abrigam coleções etnográficas. (Benchimol; Pinheiro, 2009, p. 2.437)

Assim, o objeto etnográfico ou objeto de museu, encontrase no entremeio das ciências da informação, mas também das ciências sociais, ao precisar do trabalho conjunto de profissionais diversos para traçar a sua história, desde seus produtores até a sua vivência dentro do espaço museal. Embora Benchimol e Pinheiro (2009) usem a terminologia objeto etnográfico para definir objetos da cultura material de determinada etnia ou sociedade, a definição objeto de museu, no entendimento particular, descreve melhor esse artefato dentro do espaço museal, pois o mesmo já passou pelos processos de musealização, o qual passa a ser visto como um documento.

Um "objeto de museu" é uma coisa musealizada, sendo "coisa" definida como qualquer tipo de realidade em geral. A expressão "objeto de museu" quase poderia passar por pleonasmo, na medida em que o museu é não apenas um local destinado a abrigar objetos, mas também um local cuja função principal é a de transformar as coisas em objetos. (Conceitos, 2013, p.68)

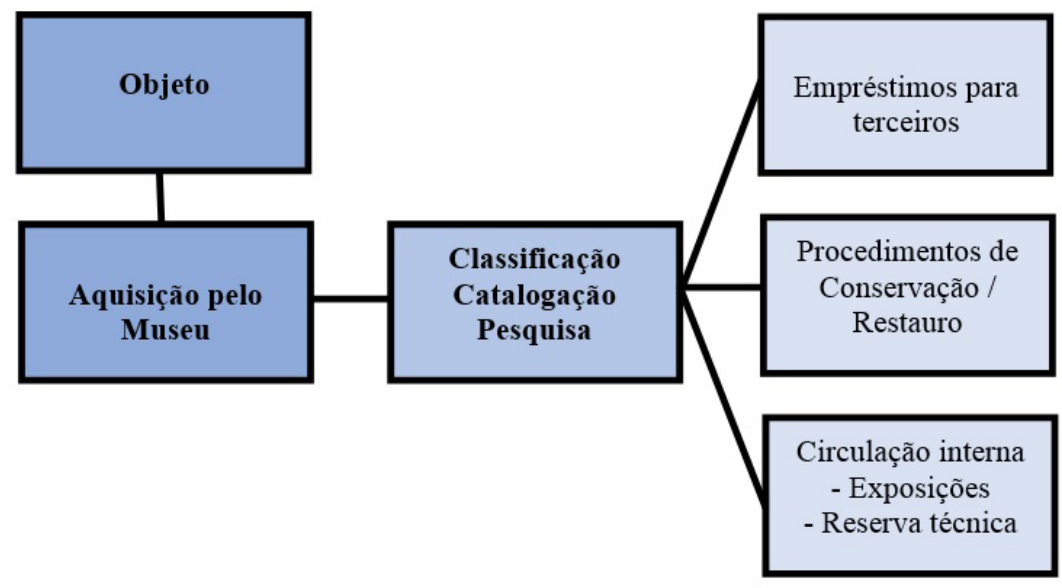

ISSN 1852-060X (impreso) / ISSN 1852-4826 (electrónico)
Figura 1. Etapas da biografia do objeto. Autoria: Priscila de Jesus

Figure 1. Steps of the object's biography. Authorship: Priscila de Jesus 
Desta forma uma peça ao ser musealizada deixa de ser "coisa" e passa a ser um "objeto" ou "documento", adquirindo um novo status e se torna mais, pois além da sua função original, ele passa a ser também um vetor comunicacional de uma memória, uma identidade, uma cultura, uma sociedade.

Essas ações que compõem as atividades desenvolvidas pelos profissionais da área museal, podem ser realizadas com objetos dos mais diversos tipos e suportes, e consistem na análise das etapas pelas quais um objeto passa até se tornar patrimônio musealizado, ou seja, a sua retirada de seu contexto primário para que se integre em uma nova categoria de análise, agora como objeto museal. (Jesus, 2014, p. 100)

Para Cury (2005) o ato de musealizar algo envolve "[...] uma série de ações sobre os objetos, quais sejam: aquisição, pesquisa, conservação, documentação e comunicação" (Cury, 2005, p. 26). Tais ações, desenvolvidas no ambiente museal por seus profissionais, permitem uma maior compreensão e preservação de informações sobre o objeto, bem como sua vida e possibilidades de comunicação. O processo de musealizar algo segue um ciclo, o qual inicia no momento em que é atestado como necessário para representar uma determinada sociedade e se tornar parte de uma instituição museal e seu discurso expositivo.

Ao se trabalhar com objetos de cultura material, sobretudo africana, as tensões na compreensão dessa representação dos objetos e do imaginário do visitante, mostram as tensões vivenciadas diariamente no trabalho museal. $E$ o imaginário do visitante é algo que o museólogo e a própria narrativa expositiva não conseguem controlar, pois todas as interpretações e associações serão traçadas a partir das experiências e vivências de seu visitante, tornando-se, assim, únicas e multifacetadas. Desta forma surgiu o interesse na pesquisa de um par de pesos para medir ouro em pó, ainda na graduação em Museologia, e o posterior revisitar desse trabalho, agora como professora de Museologia, para uma discussão de biografia a partir daqueles dois objetos.

Embora a perpetuação de grande parte das tradições e das memórias dos grupos étnicos africanos tenham se dado pela oralidade é possível se verificar a existência de uma diversidade de grupos que conhecessem e utilizassem a escrita, o que se traduz na preservação das suas culturas imaterial e material. A exemplo das produções de arte e seu caráter simbólico na produção de imagens africanas.

enquanto no século XIX e primeira metade do século XX os museus nacionais difundiram e pesquisaram questões raciais, por um viés biológico, os museus do final da segunda

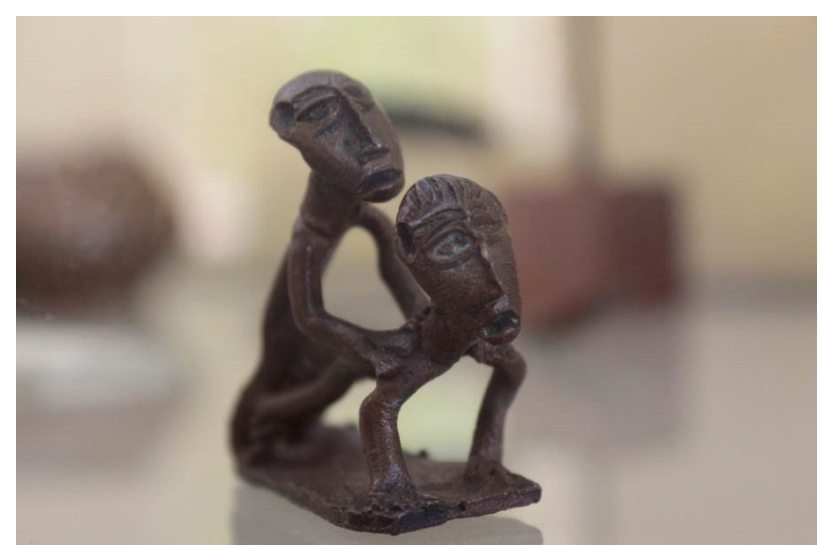

Figura 2. Casal 02, Peso para medir ouro em pó. Foto: Robson Silva.

Figure 2. Couple 02, Weight to measure powdered gold. Photo: Robson Silva.

metade do século $X X$ começaram a se preocupar com a questão das identidades territoriais e nacionais, sobretudo com os movimentos na América Latina, na qual se destaca a Mesa Redonda de Santiago do Chile (1972) e o surgimento da Nova Museologia, que buscavam transformar o museu em uma instituição de engajamento com o social, sobretudo com as comunidades próximas à instituição. (Jesus, 2013, p. 06)

Pretende-se, a partir das discussões de cultura material africana e tomando como parâmetro as discussões de arte e metalurgia africana, compreender um par de pesos para medir ouro em pó, inseridos em um contexto museal, o Museu Afro-Brasileiro (MAFRO/CEAO/UFBA), e suas implicações no cotidiano e no culto à fertilidade, a partir da compreensão da sua biografia, focando o contexto cultural e social do local de origem dos objetos. Para isso torna-se necessária a compreensão do significado da representação do ato sexual nas esculturas de origem africana, ao destacar a funcionalidade e a simbologia dos bronzes nos grupos sociais localizados na região do antigo reino do Benin, atual Nigéria.

A produção escultórica analisada apresenta duas características principais: o uso do bronze e o culto à fertilidade. O culto à fertilidade será um fator relevante nas manifestações culturais dos grupos sociais africanos localizados na região que compreende o antigo Reino do Benin, localizado hoje na região da Nigéria, simbolizando a permanência e perpetuação da sua sociedade, relaciona-se ao cotidiano destes por meio de uma relação fertilidade/fecundidade da mulher/ da terra, podendo ser associado às explicações da origem da vida.

\section{Objetivos e Metodologia}

A pesquisa busca realizar uma análise da noção 
de biografia do objeto, não no sentido de a quem pertenceu, mas sim o porquê da sua existência em seu contexto cultural e social, o objeto enquanto suporte da informação em si mesmo, ou seja, enquanto documento possível de interpretações e interações. Assim, parte-se para compreender esses objetos de museus enquanto produtos de uma dada cultural material, ou seja, enquanto "[...] suporte material, físico, imediatamente concreto da produção e da reprodução da vida social [...]" (Meneses, 1983, p. 112).

Usou-se também da análise de características intrínsecas e extrínsecas do objeto (Ferrez, 1994), uma vez que o objeto em si traz as informações que estão inerentes nele quanto ao seu design, forma, composição, que são visíveis aos olhos de quem o vê, que constituem as informações iniciais, obtidas no primeiro contato, como também as informações que são disponibilizadas ao público como mostra a Figura 3.

Utilizou-se, ainda, a revisão de literatura, levantamento documental do objeto no museu, a partir das suas fichas catalográficas (documentação interna do museu), como mostra as Figuras 4 e 5 e pesquisas realizadas pelo núcleo de Documentação.

Tais documentos permitem entender a trajetória do objeto dentro do espaço museológico e suas abordagens de interpretação por parte de suas equipes, permitindo reflexões sobre a visão ocidental e oriental a partir da representação de cenas de cópula em objetos.

\section{Discussões e Resultados}

Os objetos que foram analisados constituem de um par de pesos para medir ouro em pó que tiveram sua entrada no Museu Afro-Brasileiro, Salvador/Bahia/Brasil, em janeiro de 1983, por meio de doação da Sra. Benedita Damasceno'. Os objetos, datados como produzidos no século XX, deram entrada como um conjunto e assim

1 Informações obtidas a partir da ficha catalográfica do objeto ( ${ }^{\circ}$ 0012) no Museu Afro-Brasileiro.

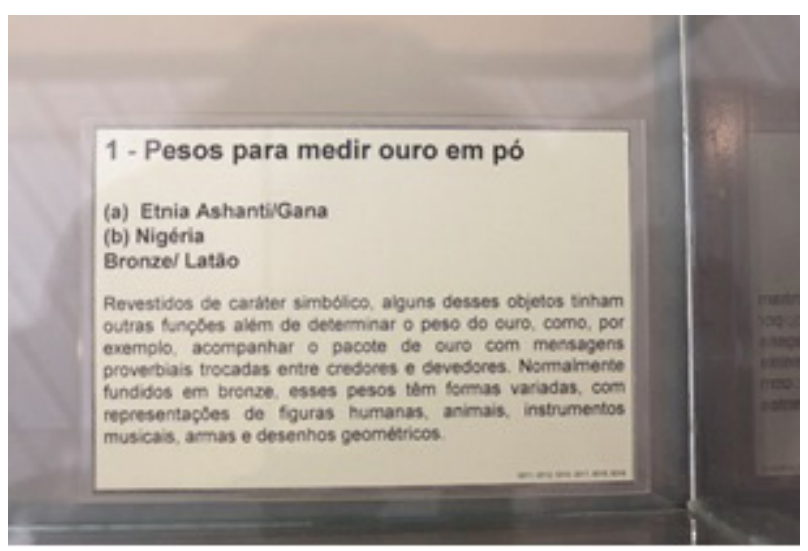

Figura 3. Etiqueta dos objetos. Foto: Robson Silva.

Figure 3. Label of objects. Photo: Robson Silva.

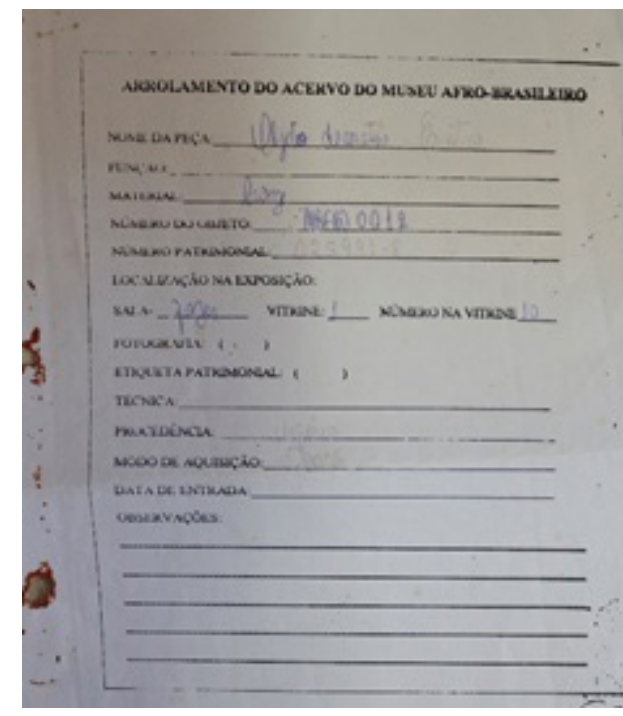

Figura 4. Ficha de arrolamento do objeto da década de 1980. Foto: Robson Silva.

Figure 4. Listing of the object from the 1980s. Photo: Robson Silva.

permaneceram durante todo processo de documentação dentro do museu, em sua ficha catalográfica inicial estão descritos apenas como objetos decorativos. Na ficha não há mais informações sobre a doadora ou o objeto antes de sua entrada no museu, além das poucas apresentadas. No entanto, a informação sobre a doadora aparece posteriormente, na ficha dos objetos por sala, no qual constam mais informações como o local de origem do par de pesos.

Na concepção expositiva do museu, os objetos estão expostos no módulo de metalurgia, juntamente com outros objetos em bronze. Na vitrine eles dialogam com outros pesos com representações fitomórficas e um de jogo de ayố2.

O Objeto 01 (Figura 6) e o Objeto 02 (Figura 7) apresentam a figura masculina na posição sobre a mulher, bem como a valorização - no que diz respeito ao tamanho - dos órgãos sexuais masculinos. Nota-se que não há um detalhamento maior do bronze, o que se supõe a sua atribuição ao século XX.

Os corpos são representados de forma simplificada e estilizada, são prolongamentos em bronze que formam os troncos, as pernas e os braços das imagens. Há a presença de ondulações - possíveis marcas de solda - nas áreas de junção como o pescoço e os braços que ligam ao tronco do corpo. A representação dos dedos das mãos e dos pés contam com apenas três dedos achatados cada, infere-se que uma vez dada o tamanho dos objetos o artista não deu um detalhamento maior às figuras.

No entanto, essa mesma simplificação das formas não é

2 Jogo que envolve cálculos matemáticos. 


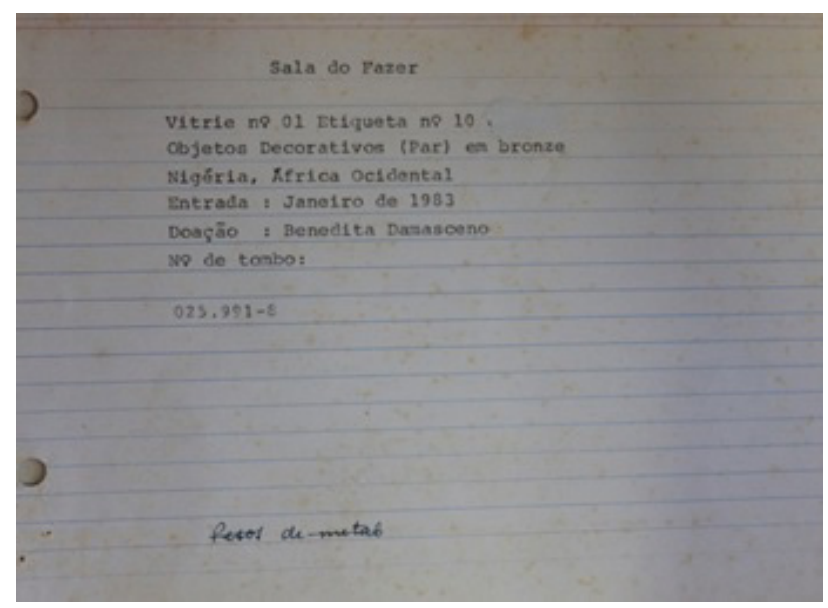

Figura 5. Ficha do objeto. Foto: Robson Silva.

Figure 5. Object file. Photo: Robson Silva.

vista nas representações das cabeças, é possível destacar as semelhanças na composição das cabeças masculinas ou femininas, onde as figuras masculinas apresentam rostos mais redondos, nariz proeminente e largo. Já as figuras femininas apresentam um rosto mais oval, com queixo e nariz afilados e uma sugestão de penteados.

Embora na exposição, por meio de textos e etiquetas, apresente-se uma visão geral do objeto e seu significado, percebeu-se que o objeto não contava com uma documentação que apresentasse mais informações além das levantadas em 1983, quando da entrada do objeto no museu. Percebe-se que os processos museológicos, como documentação e pesquisa ainda precisam ser revistos e atualizados para incluir pesquisas que envolvam a biografia dos objetos.

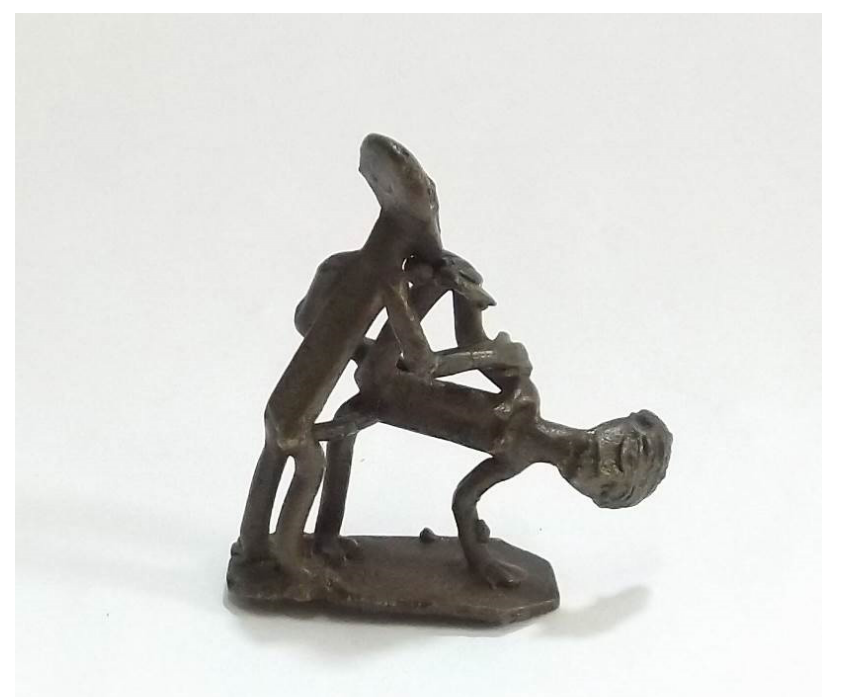

Figura 6. Objeto 01, peso para medir ouro em pó. Foto: Acervo MAFRO

Figure 6. Object 01, weight to measure powdered gold. Photo: MAFRO Collection
O MAFRO/UFBA destaca-se por sua linguagem expositiva pautada, sobretudo, na estética africana, apresentando técnicas e evidenciando o caráter mais artístico dos objetos lá expostos. De acordo com Lody, "O MuseuAfro-Brasileiro também funciona como quase-espelho de um ideário de estética afro que é contactado como se os visitantes emocionalmente estabelecessem uma fala com os objetos, tantas vezes assim se reconhecendo." (LODY, 2005, p. 213). Para entender o objeto de museu, torna-se essencial estabelecer relações com outras áreas do saber, como a História, Antropologia, Ciência da Informação, Artes e Museologia, para entende-lo enquanto um objeto de museu e poder realizar os processos de comunicação para com o visitante (BENCHIMOL; PINHEIRO, 2009).

Desta forma, para entender o par de pesos para medir ouro em pó, como cultura material africana e objeto de museu realizou-se o estudo em particular dos processos de metalurgia e a estética da produção em bronze do antigo reino do Benin, parte da atribuição de origem dos objetos, sendo da Nigéria. No que tange a produção imagética autores como Eisenhofer (2000) e Meyer (1991) apresentam discussões sobre a representação do corpo humano como uma cena, uma mensagem tridimensional, na qual o artista apresenta para seu comprador uma comunicação de caráter moral ou educacional. Essa mensagem, expressada por meio do objeto de cultura material, acaba por ser reproduzida pelos indivíduos que constituem essa sociedade, transformando-se num veículo de comunicação. É essa função que desempenha alguns objetos que compõem parte do acervo do Museu Afro-Brasileiro da Universidade Federal da Bahia, em particular um par de pesos para medir ouro em pó.

É possível dizer que a produção escultórica em bronze ilustra o universo simbólico e das tradições onde estão inseridos os objetos e a sociedade que o produziu, podendo expressar regras de conduta ou a sabedoria de uma sociedade. É importante destacar que a elevação, no ocidente, da produção imagética africana ao status de arte só foi possível com a sua entrada nos espaços museais e sua legitimação, como ressalta Silva e Ferreira ao dizer que "Independentemente de sua classificação como etnográficos ou artísticos, interessa aqui destacar que os objetos africanos só foram legitimados a partir do momento em que foram inseridos em acervos museológicos" (SILVA, FERREIRA, 2015, p. 05).

Meyer (1991) destaca ainda o problema de diagnosticar as origens tanto de início de uso, influências e técnicas de feitura da arte no antigo Benin, independente de serem silhuetas humanas, representações zoomórficas em bronze ou marfim. Outro problema destacado foi que as produções pertencentes aos séculos XVI e XVII apresentavam uma qualidade e elaboração estética notadamente superior às produções dos séculos sequentes. No entanto, vale ressaltar que em outras sociedades do continente africano a existência e a 


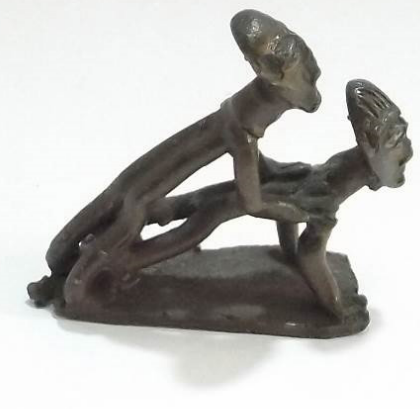

Figura 7. Objeto 02, peso para medir ouro em pó. Foto: Acervo MAFRO

Figure 7. Object 02, weight to measure powdered gold. Photo: MAFRO Collection

utilização do bronze e do chumbo é notadamente antiga, datando do século VI, no Senegal e entre os séculos VIII e IX, na Mauritânia.

Com as constantes invasões e divisões do território africano nos séculos XVII e XVIII a situação militar da cidade capital do antigo Reino do Benin apresentou as suas primeiras rupturas, culminando com o saque realizado em 1897, por soldados britânicos, que marcou o fim da autonomia do reino e de sua arte em bronze (MEYER, 1991). Uma grande quantidade de acervo em bronze no Benin, em especial do Palácio Real, se espalhou pelo mundo, dando entrada em coleções particulares e, posteriormente, compondo coleções de grandes museus do mundo, a exemplo do British Museum.

Entre as representações destacadas na produção em bronze, ressalta-se a presença de imagens com casais em cena de cópula, que podem ser interpretadas em grande parte, como representações de fertilidade e perpetuação da espécie, segundo Combalía, contém "[...] una descripción realista y a veces casi surrealista de motivos sexuales." (2004, p. 21). Para Combalía (2004) há uma inadequação do termo "erótico" para designar essas imagens sexuais na cultura africana, como entendemos no ocidente, pois a percepção e compreensão de erótico entre ocidente e oriente não se correspondiam. Enquanto os ocidentais, nos séculos XVI e XVII, viam o ato sexual como um meio para sua descendência, à sua linhagem familiar, as sociedades africanas viam no ato sexual um meio de perpetuação do seu grupo, da sociedade a que pertenciam.

No continente africano, a sexualidade tem por base os ritos de iniciação, nos quais os homens são associados à força/destruição e a mulher à vida/renovação, como elucida Combalía "[...] la sexualidad en Áfricas se rige por unos ritos iniciáticos que asocian lo masculino a la guerra y lo femenino a la fertilidad." (2004, p. 22). Dicotomia esta que Munanga e Cerávolo (1987) também sinalizam e ampliam ao destacar a divisão das funções dos homens e das mulheres no plano social e ritual, que se opõem nesse universo africano. Nessas relações de fertilidade/ fecundidade, tanto o ser humano como a natureza são temas complementares, que se ligam, não havendo uma dissociação.

Para algumas sociedades africanas, como as que se estabeleceram na Nigéria, o sexo e os atributos sexuais do homem e da mulher são vistos com respeito e discrição, essa importância torna-se presente nas suas produções artísticas e de rituais, onde os atributos sexuais são esculpidos de forma nítida ou em maiores proporções em relação ao corpo. Como informa Lentini, "Si hablamos de sexo y género hay que saber cuál es el universo simbólico relacionado con las reglas matrimoniales, las conductas sexuales y los sistemas de parentesco." (2004, p. 40). O teor simbólico das expressões corporais nas artes africanas deve ser destacado nas exposições museológicas, sobretudo seu caráter social e ritualístico.

Embora a definição de museu tenha sistematicamente se ampliado ao longo dos séculos, de espaço de contemplação, para salvaguarda, na atualidade há ações para se tornar mais amplo, diversificado e inclusivo. O museu a partir de 2007 passou a ser definido como: "uma instituição permanente sem fins lucrativos, ao serviço da sociedade e do seu desenvolvimento, aberta ao público, que adquire, conserva, investiga, comunica e expõe o património material e imaterial da humanidade e do seu meio envolvente com fins de educação, estudo e deleite." (CONSELHO, 2015).

Na última reunião do Conselho Internacional de Museus (ICOM), realizada nos dias 21 e 22 de julho de 2019, em Paris, foi proposta para votação a definição alternativa:

Los museos son espacios democratizadores, inclusivos y polifónicos para el diálogo crítico sobre los pasados y los futuros. Reconociendo y abordando los conflictos y desafíos del presente, custodian artefactos y especímenes para la sociedad, salvaguardan memorias diversas para las generaciones futuras, y garantizan la igualdad de derechos y la igualdad de acceso al patrimonio para todos los pueblos.

Los museos no tienen ánimo de lucro. Son participativos y transparentes, y trabajan en colaboración activa con y para diversas comunidades a fin de coleccionar, preservar, investigar, interpretar, exponer, y ampliar las comprensiones del mundo, con el propósito de contribuir a la dignidad humana y a la justicia social, a la igualdad mundial y al 
bienestar planetario. (CONSELHO, 2019)

O conceito apresentado gerou novas discussões como a desvinculação de termos como educação do conceito de museu, que abriu para os novos questionamentos sobre o que é realmente um museu e suas atribuições, abrindo para os profissionais um canal para encaminhar suas reflexões e possíveis novos conceitos. Desta forma, o ICOM tenta trazer para seu conceito as várias percepções de mundo, a diversidade e a igualdade. Embora a alteração do conceito esteja em votação e, essa tenha ganhado uma ampla participação e discussão dos profissionais de museu, percebe-se que mais um novo passo foi dado no intuito de tornar os museus mais acessíveis e em diálogo com seu acervo e as diversas comunidades.

Uma vez que a discussão sai de um grupo pré-determinado do ICOM e passa a ser uma discussão de todo e qualquer profissional da área que queira contribuir, amplia as possibilidades de discussão e compreensão do museu real, aquele vivenciado pelo seu corpo técnico e que nem sempre está em sincronia com as discussões do ICOM por questões como barreira linguística, distanciamento conceitual-prático e, sobretudo, econômico. Essa democratização passa também pelas pesquisas que são desenvolvidas dentro do espaço museal e, no Brasil, os estudos de cultura material africana ainda não refletem a diversidade dos seus acervos.

\section{Considerações Finais}

Embora o cenário museal brasileiro tenha ampliado com o número de cursos de museologia e maior qualificação dos profissionais, os museus ainda sofrem com falta de profissionais, recursos para o desenvolvimento de pesquisas, documentação e exposição. A exposição do Museu Afro-Brasileiro da UFBA, apresenta os objetos enquanto produções de uma determinada sociedade que dominava a metalurgia. Cabe ressaltar que embora o museu apresente esse aspecto mais técnico, ele busca transmitir a simbologia por trás da concepção imagética das imagens para o público que a observa, levando-o a uma reflexão crítica do objeto.

A maneira como a representação do ato sexual se faz nas esculturas deve suscitar uma análise para além de uma arte erotizada, ou como objeto decorativo ${ }^{3}$, mas, sim como parte de uma cultura material africana que expressa em suas linhas e contornos a concepção social e religiosa de uma sociedade, ligada à fertilidade, à união e à continuidade do grupo, como agentes difusores de mensagens sociais.

Os museus do século $X X I$, mais que um local de salvaguarda, consistem em um local de reflexão

\footnotetext{
3 Designação europeia que reflete sua visão, na qual atribui um sentido decorativo a uma produção que inicialmente não se propunha exclusivamente a tal função
}

e informação, possibilitando que se tenha acesso às narrativas possíveis de um determinado objeto. Compreender de onde viemos, quem somos e para onde vamos a partir do momento que se conhece a sua história por meio dos objetos de museu. O que é o museu? Se não uma instituição que precisa se reinventar e se adequar ao presente, tentando não esquecer, preservando as memórias de sua sociedade e convivendo com as demandas de uma sociedade do futuro.

\section{Referências}

Benchimol, A., Pinheiro, L.V.R. (2009) Objeto etnográfico como documento e informação. In: ENANCIB 2009 Encontro Nacional de Pesquisa em Ciência da Informação (10), João Pessoa. Anais X ENANCIB 2009, GT 9 - Museu, Patrimônio e Informação. João Pessoa: ANCIB, PPGClUFPB, 2009.p. 2436-2450. 1 CD ROM. Disponível em: http://ridi.ibict.br/bitstream/123456789/71/1/ ALEGRIAEnancib2009.pdf, Acesso em setembro de 2019.

Combalía, V. (2004) Lo que yo imagine. El Primer Eros: África, America, Oceania. Barcelona: Institut de Cultura, Lunwerg editores, p. 15-31.

Conselho Internacional de Museus (2015) Definição: Museu. Disponível em http://icom-portugal. org/2015/03/19/definicao-museu/ [acesso em 27 de abril de 2019]

Conselho Internacional de Museus (2019) Definición de museo. Disponível em https://icom.museum/es/ actividades/normas-y-directrices/definicion-del-museo/ [acesso em 02 de setembro de 2019].

Desvallées, A., Mairesse, F. (editores) (2013) CONCEITOSChave de Museologia. Tradução Soares, Bruno Brulon e Cury, Marilia Xavier. São Paulo: ICOM, Pinacoteca do Estado de São Paulo, Secretaria de Estado da Cultura.

Cury, M.X. (2005) Exposição: concepção, montagem e avaliação. São Paulo: Annablume.

Eisenhofer, S. (2000) Le royaume de Bénim et sés arts de cour. Artsd'Afrique. Paris: Gallimard.

Ferreira, L.G. (2011) Classificações instáveis e permeáveis: Cultura material africana nos museus. Revista Brasileira do Caribe, São Luis, Vol. XI, n. 22, Jan-Jun 2011, p. 79-99.

Ferrez, H. D. (1994) Documentação museológica: teoria para uma boa prática. Cadernos de Ensaios n.2: estudos de museologia. Rio de Janeiro: Minc/Iphan, 1994.

Jesus, P.M. de (2019) Uma reflexão sobre o processo de musealização: o patrimônio imaterial nos espaços museais. Cadernos de Sociomuseologia, Lisboa, n. 4, v. 48, p. 95-110, 2014. Disponível em: <http://revistas. 
ulusofona.pt/index.php/cadernosociomuseologia/article/ viewFile/4633/3138>. Acesso em: 09 de agostode 2019.

Jesus, P.M. de (2019) Do mito do embranquecimento à valorização de uma identidade negra: os museus brasileiros e seu papel social. Anais do IX ENECULT. SALVADOR: UFBA, 2013. p. 1-9. Disponível em: http:// www.cult.ufba.br/enecult/anais/edicao-2013/acesso em 15 de setembro de 2019 .

Lara, M.L.G. de (2001) O unicórnio (o rinoceronte, o ornitorrinco...), a análise documentária e a linguagem documentária. DataGramaZero, 2(6).

Lentini, J (2004) Las Formas del Deseo. El Primer Eros: África, America, Oceania. Barcelona: Institut de Cultura, Lunwerg editores, 2004, p. 39-73.

Lody, R. (2005) O negro no museu brasileiro: construindo identidades. Rio de Janeiro: Bertrand Brasil, 2005.

Meneses. U.T. (1983) A Cultura Material no Estudo das Sociedades Antigas. Revista de História, 11 (nova série).

Meneses, U.T. (1998) Bezerra de. Memória e Cultura Material: documentos pessoais no espaço público.
Estudos Históricos, 11(21), 89-104.

Meyer, L. (1991) Pour le prestige d'um gran roi, le bronze el l'ivoire. Afrique noire: masques, sculptures, bijoux. Paris: Terrail, 1991.

Miller, D. (2013) Trecos, troços e coisas: estudos antropológicos sobre a cultura material. Rio de Janeiro: Editora Zahar, 2013.

Munanga, K e Cerávolo, S.M. (1987) Fertilidade da Terra e Fecundidade da Mulher: símbolos e suportes materiais nas sociedades negro-africanas. Dédalo. São Paulo: USP, p. 7-21.

Silva, A., Ferreira, L.G (2017) Entre o Etnográfico e o Artístico Cultura Material Africana no Cenário Museológico. Revista Tucunduba, América do Norte, 1, ago. 2010. Disponível em: http://www.revistaeletronica. ufpa.br/index.php/tucunduba/article/view/22/15. Acesso em: 27 Set. 2017.

Young, T.C. (1988) Desde Heródoto, a história tem sido um conceito válido? American Antiquity 53 (tradução não publicada por IrmhildWüst / Universidade Federal de Goiás), p. (1):7-12. 